\title{
Failure Analysis of Large-Scale Wind Power Structure under Simulated Typhoon
}

\author{
Zihua Zhang, Junhua Li, and Ping Zhuge \\ College of Civil Engineering and Environment, Ningbo University, Ningbo 315211, China \\ Correspondence should be addressed to Zihua Zhang; zhangzihua@nbu.edu.cn
}

Received 5 January 2014; Revised 18 June 2014; Accepted 23 June 2014; Published 14 July 2014

Academic Editor: Gisele Mophou

Copyright ( 2014 Zihua Zhang et al. This is an open access article distributed under the Creative Commons Attribution License, which permits unrestricted use, distribution, and reproduction in any medium, provided the original work is properly cited.

\begin{abstract}
Recently, a number of wind power structures in tropical cyclone zones are damaged by typhoon. In order to study the failure mechanics and failure modes of wind power structure subjected to typhoon, the typhoon wind field in Dongtai wind farm is simulated based on the classical autoregressive (AR) model and a regional power-spectrum-density (PSD) model, and the simulated spectrum is verified to be in good agreement with the target spectrum. An integrated finite element (FE) model of wind power structure, composed of rotor, nacelle, tower, pile cap, and PHC piles, is established. Modal analysis reveals that pile stiffness decreases the structure's natural frequencies, especially for high order frequencies. Structural responses under the simulated typhoon are calculated by dynamic analysis. Results show that tower buckling is the most prone failure mode of the structure. The horizontal displacement of the hub and the axial force of the most unfavorable piles are both under the limit. This study provides a way to the antityphoon design of large-scale wind power structures.
\end{abstract}

\section{Introduction}

With the increase of investment of clean energy from governments, wind energy has grown enormously all over the world in the past decade and will stand to benefit from its role as both a source of energy security and a key to solving the problem of climate change in the future. Compared with the year 2011, wind power market grew by more than $10 \%$ in 2012, and the new global total installed wind power capacity at the end of 2012 was $282.5 \mathrm{GW}$, representing cumulative market growth of more than 19\% [1]. And China has already taken the leadership position of cumulative wind power capacity in 2011.

It should be noted that more and more wind farms are established in tropical cyclone zones, making the wind turbine and its support structure have to face the threat of typhoon. For instance, typhoon Maemi struck the Miyakojima Island with an average speed of $38.4 \mathrm{~m} / \mathrm{s}$ and a maximum gust of $74.1 \mathrm{~m} / \mathrm{s}$ on September 11, 2003. All of the wind turbines on the island were extensively damaged. Three of six turbines collapsed and the others suffered from destructive damage, whose blade were broken or the nacelle cover drooped. Based on FEM simulation and wind response analysis, Ishihara et al. [2] found that the overlarge maximum bending moment was the reason for the buckling and collapse of the tower. In September 2003, typhoon Dujuan attacked the Honghaiwan wind farm of Guangdong, and varying degrees of damage were caused to thirteen wind turbines. In August 2006, typhoon Saomai passed through the Hedingshan wind farm of Zhejiang and led to collapse of five wind turbines [3].

Although massive losses in coastal wind farms have been caused by typhoon, the failure mechanism and failure modes of wind power structures are not clear yet. Generally, modern wind turbines are designed mainly according to the international standard (IEC 61400-1) [4] that is based on European and North American conditions without the experience from areas attacked by typhoon. On the other hand, designers and engineers usually pay more attention to the wind turbine, including rotor, nacelle, and tower, but the soil-structure interaction (SSI) is always out of consideration. The two reasons above result in the ultimate wind load and the structural responses are inevitably underestimated; no need to mention that the characteristic of typhoon is essentially different from the normal wind. Recently, attention has been increasingly paid to the typhoon-induced damage of wind turbines. 
Li et al. [3] analyzed the data of typhoon Saomai when it was passing through Hedingshan wind farm. It was pointed out that the violent wind, drastic turbulence, and sudden change of wind direction were major factors of wind turbine failures. From the view of economics, Clausen et al. [5] estimated that the cost of wind turbine in tropical cyclone zones is $20-30 \%$ more than that in normal areas. Chou et al. [6] examined the causes of blade damage of five wind turbines in Changhua Coastal Industrial Park of Taiwan. It was found that longterm effects such as blade fatigue could cause local crack damage and delamination, and the actual blade damage occurred mainly on the back edge of the blade near the wing section.

In offshore wind turbines, the structural responses are driven not only by wind but also by water wave. Consequently, the dynamic analysis of offshore wind turbines is more complex than that of land-based ones. Karimirad and Moan [7] employed an advanced blade element momentum theory, panel method, and the Morison formula to study the dynamic structural and motion responses of a spar-type floating offshore wind turbine caused by stochastic nonlinear wave and wind loads in harsh and operational environmental conditions. It is found that the wind turbulence affects power production rather than the dynamic motion and structural responses. Based on the Arbitrary LagrangianEulerian (ALE) method and FEM, Zhang et al. [8] simulated a wind-induced aqueduct-water coupling system installed with isolated bearings. It is found that the resonance can be eliminated under high-order-frequency excitation and may happen when the excitation frequency is close to the firstorder water sloshing frequency. Karimirad and Moan [9] presented a stochastic dynamic response analysis of a tension leg spar-type wind turbine subjected to wind and wave actions. To study the power performance and structural integrity of the system, negative damping, rotor configuration, and tower shadow effects are discussed.

This paper aims at analyzing the potential failure modes of wind power structure subjected to typhoon and is organized as follows. The location and wind condition of Dongtai wind farm is introduced in Section 2. In Section 3, the fluctuating wind speed of typhoon is simulated and verified based on a regional PSD mode and the AR method, followed by a presentation of wind load calculation in the same part. A FE model of a $1.5 \mathrm{MW}$ wind turbine with pile foundation is established in Section 4, and structure's natural frequencies and windinduced responses are calculated by elastic dynamic analysis. The failure modes of the wind power structure are concluded finally.

\section{Farm Location and Wind Condition}

Dongtai wind farm is located in Dongtai City, Jiangsu Province, southeastern China, at $120^{\circ} 54^{\prime}$ east latitude and $32^{\circ} 47^{\prime}$ north longitude, as shown in Figure 1. Totally, one hundred and thirty-four $1.5 \mathrm{MW}$ wind turbines are installed in a $60 \mathrm{~km}^{2}$ site. Wind resource in this area is rich in east and poor in west, forming a long and narrow wind speed surging region.

Although Dongtai is not a typhoon landing site in general, it still has to face the threat of typhoon. For example, in 2009,
TABLE 1: Tropical cyclone classification.

\begin{tabular}{lcc}
\hline Classification & $\begin{array}{c}\text { Average wind speed } \\
(\mathrm{m} / \mathrm{s})\end{array}$ & Wind scale \\
\hline Tropical depression (TD) & $10.8-17.1$ & $6-7$ \\
Tropical storm (TS) & $17.2-24.4$ & $8-9$ \\
Severe tropical storm (STS) & $24.5-32.6$ & $10-11$ \\
Typhoon (TY) & $32.7-41.4$ & $12-13$ \\
Severe typhoon (STY) & $41.5-50.9$ & $14-15$ \\
Super typhoon (SuperTY) & $\geq 51.0$ & $\geq 16$ \\
\hline
\end{tabular}

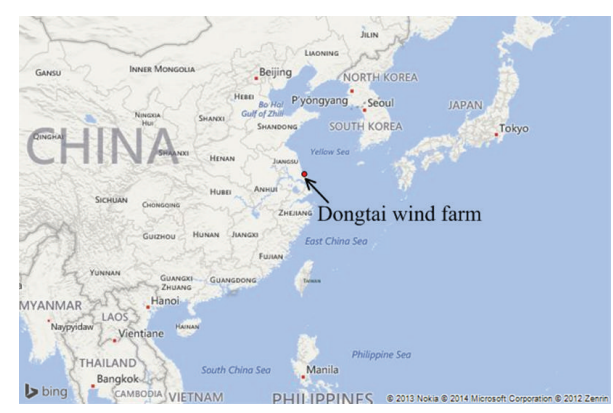

FIgURE 1: Location of Dongtai wind farm.

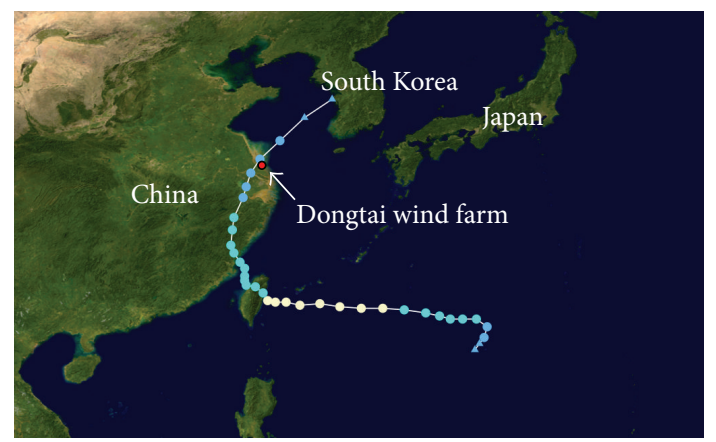

FIGURE 2: The track map of typhoon Morakot.

typhoon Morakot passed through Dongtai with an average wind speed of $33 \mathrm{~m} / \mathrm{s}$ and moved into East China Sea, as shown in Figure 2. In 2012, typhoon Damrey landed in Xiangshui of Jiangsu Province with an average wind speed of $35 \mathrm{~m} / \mathrm{s}$ and brushed past Dongtai, as shown in Figure 3. It should be noted that, according to the extreme wind speed model (EWM) [4], the extreme wind speed with a recurrence period of 50 years of the wind farm is $24.37 \mathrm{~m} / \mathrm{s}$, which is far below the average wind speed of the two typhoons mentioned above.

According to [10], tropical cyclones are classified as 6 grades, as shown in Table 1 . It can be seen that the lower limit of typhoon's average wind speed is $32.7 \mathrm{~m} / \mathrm{s}$, which is employed to simulate the fluctuating wind speed in this paper.

\section{Typhoon Wind Load Simulation}

3.1. PSD Model of Typhoon. Natural wind consists of two components, that is, mean wind and fluctuating wind, and the 


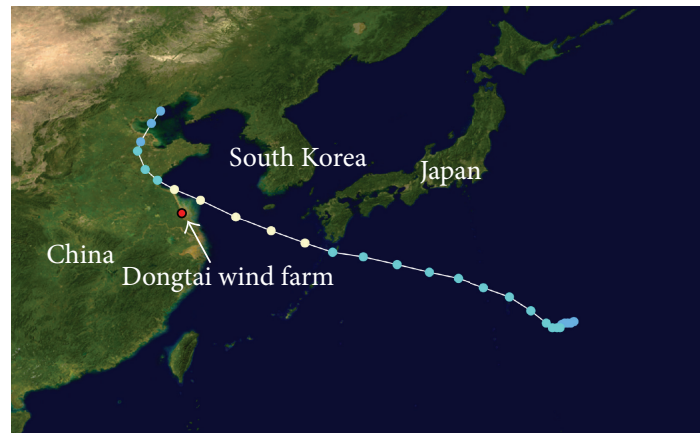

FIGURE 3: The track map of typhoon Damrey.

latter represents turbulence and randomness. Consequently, the instantaneous velocity of wind can be described as

$$
U_{z}(t)=\bar{U}_{z}+u_{z}(t)
$$

where $\bar{U}_{z}$ and $u_{z}(t)$ are the mean wind velocity and the fluctuating wind velocity at height $z$ and time $t$, respectively. $\bar{U}_{z}$ obeys the logarithmic law and can be described as [11]:

$$
\bar{U}_{z}=\bar{U}_{\text {ref }} \frac{\ln \left(z / z_{0}\right)}{\ln \left(z_{\text {ref }} / z_{0}\right)},
$$

where $\bar{U}_{\text {ref }}$ is a reference wind velocity measured at the reference height $z_{\text {ref }}$, and $z_{0}$ is the roughness length.

According to the random vibration theory, the fluctuating wind velocity can be regarded as a zero-mean Gaussian process and described by the power-spectrum-density (PSD) model in the frequency domain [12]. A lot of empirical spectrum models, mostly for the longitudinal wind velocity, have been published, such as von Karman spectrum [13], Davenport spectrum [14], and Simiu spectrum [15]. Considering the features of typhoon, such as strong turbulence, high wind speed, and significant regional characteristics, the PSD model of typhoon is essentially different from that of normal wind. Shi et al. [16] proposed an empirical spectrum that does not change with altitude, according to the observed data in Shanghai since 1956 and taking the characteristics of the typhoon turbulence scale varying with altitude into account. Considering that the distance between Dongtai and Shanghai is acceptable, Shi's spectrum is employed here. The model is defined as

$$
\begin{gathered}
S_{v}(n)=\frac{5.46 k \bar{v}_{10}^{2} x^{2.4}}{n\left(1+1.5 x^{2}\right)^{1.4}}, \\
x=\frac{1200 n}{\bar{v}_{10}}, \\
n=\frac{\omega}{2 \pi},
\end{gathered}
$$

where $S_{v}(n)$ is the PSD of the fluctuating wind speed, $k$ is the ground roughness coefficient, $v_{10}$ is the average wind speed at the height of $10 \mathrm{~m}, n$ is the wind frequency, and $x$ is the turbulence integral scale factor.

3.2. Fluctuating Wind Speed Simulation. Discrete models of wind speed based on Box-Jenkins methods are used commonly in time-series analysis. These models, including autoregressive (AR) [17], moving average (MA) [18], autoregressive moving average (ARMA) [19], and autoregressive integrated moving average (ARIMA) models [20], are usually termed as linear filtering method and are able to reproduce the statistical properties of the fluctuating wind speed for a particular site with an acceptable computational cost. The classical AR model is employed to simulate the wind field of typhoon in this paper [21]. To generate a family of $M$ processes, the following equations are used:

$$
\begin{gathered}
\mathbf{u}(t)=\sum_{k=1}^{p} \psi_{k} \mathbf{u}(t-k \Delta t)+\mathbf{N}(t), \\
\mathbf{u}(t)=\left[u^{1}(t), \ldots, u^{M}(t)\right]^{T}, \\
\mathbf{u}(t-k \Delta t)=\left[u^{1}(t-k \Delta t), \ldots, u^{M}(t-k \Delta t)\right]^{T}, \\
\mathbf{N}(t)=\left[N^{1}(t), \ldots, N^{M}(t)\right]^{T},
\end{gathered}
$$

where $u^{i}(t)$ and $u^{i}(t-k \Delta t), i=1, \ldots, M$, are the fluctuating wind speed at time $t$ and time $(t-k \Delta t)$, respectively, and $N^{i}(t)$ is made of normally distributed random numbers with zero mean and unit variance. $\psi_{k}$ are $M \times M$ matrices, $k=1, \ldots, p$, and $p$ is regarded as the order of the model.

The covariance between $u^{i}(t)$ and $u^{i}(t-k \Delta t)$ can be denoted as [22]:

$$
\begin{aligned}
R_{u}^{i} & {[k \Delta t] } \\
& =E\left[\left\{u^{i}(t-k \Delta t)-E\left[u^{i}(t-k \Delta t)\right]\right\}\left\{u^{i}(t)-E\left[u^{i}(t)\right]\right\}\right] .
\end{aligned}
$$

Considering that $u^{i}(t)$ and $u^{i}(t-k \Delta t)$ are stationary stochastic processes with zero mean, (10) can be rewritten as

$$
R_{u}^{i}[k \Delta t]=E\left[u^{i}(t-k \Delta t) u^{i}(t)\right]
$$


Postmultiplying (6) by $\mathbf{u}(t-k \Delta t)^{T}$ and applying mathematical expectation derive

$$
\begin{aligned}
& \mathbf{R}=\overline{\mathbf{R}} \psi, \\
& \mathbf{R}_{p M \times M}=\left[\mathbf{R}_{u}(\Delta t), \ldots, \mathbf{R}_{u}(p \Delta t)\right]^{T}, \\
& \psi_{p M \times M}=\left[\psi_{1}^{T}, \ldots, \psi_{p}^{T}\right]^{T}, \\
& \overline{\mathbf{R}}_{p M \times p M}=\left[\begin{array}{ccccc}
\mathbf{R}_{u}(0) & \mathbf{R}_{u}(\Delta t) & \cdots & \mathbf{R}_{u}[(p-2) \Delta t] & \mathbf{R}_{u}[(p-1) \Delta t] \\
\mathbf{R}_{u}(\Delta t) & \mathbf{R}_{u}(2 \Delta t) & \cdots & \mathbf{R}_{u}[(p-1) \Delta t] & \mathbf{R}_{u}(0) \\
\vdots & \vdots & \ddots & \vdots & \vdots \\
\mathbf{R}_{u}[(p-2) \Delta t] & \mathbf{R}_{u}[(p-1) \Delta t] & \cdots & \mathbf{R}_{u}[(p-4) \Delta t] & \mathbf{R}_{u}[(p-3) \Delta t] \\
\mathbf{R}_{u}[(p-1) \Delta t] & \mathbf{R}_{u}(0) & \cdots & \mathbf{R}_{u}[(p-3) \Delta t] & \mathbf{R}_{u}[(p-2) \Delta t]
\end{array}\right], \\
& \mathbf{R}_{u}(j \Delta t)_{M \times M}=\left[\begin{array}{ccc}
R_{u}^{11}(j \Delta t) & \cdots & R_{u}^{1 M}(j \Delta t) \\
\vdots & \ddots & \vdots \\
R_{u}^{M 1}(j \Delta t) & \cdots & R_{u}^{M M}(j \Delta t)
\end{array}\right], \quad j=1, \ldots, p, \\
& {\left[\psi_{j}\right]_{M \times M}=\left[\begin{array}{ccc}
\psi_{j}^{11} & \cdots & \psi_{j}^{1 M} \\
\vdots & \ddots & \vdots \\
\psi_{j}^{M 1} & \cdots & \psi_{j}^{M M}
\end{array}\right], \quad j=1, \ldots, p .}
\end{aligned}
$$

The cospectrum and the covariance function satisfy the Wiener-Khintchine equation; that is,

$$
\begin{array}{r}
R_{u}^{i k}(j \Delta t)=\int_{0}^{\infty} S_{u}^{i k}(n) \cos (2 \pi j \Delta t) d n, \\
i, k=1, \ldots, M,
\end{array}
$$

where $S_{u}^{i k}(n)$ denotes the cross-spectral density function of point $i\left(x_{i}, y_{i}, z_{i}\right)$ and point $k\left(x_{k}, y_{k}, z_{k}\right)$ and can be expressed as

$$
S_{u}^{i k}(n)=\sqrt{S_{u}^{i i}(n) S_{u}^{k k}(n)} \operatorname{coh}^{i k}(n),
$$

where $S_{u}^{i i}(n)$ represents the PSD of point $i$ associated with the process $u^{i}(t)$ and has the form of (3), and $\operatorname{coh}^{i k}(n)$ represents the coherence function of longitudinal fluctuations between point $i$ and point $k$.

Considering that wind power structure is a typical slender structure, a simplified expression of $\operatorname{coh}^{i k}(n)$ proposed by Shiotani and Avai [23] is adopted here:

$$
\operatorname{coh}^{i k}=\exp \left(-\frac{\left|z_{i}-z_{k}\right|}{L_{z}}\right)
$$

and $L_{z}$ is proposed to be 60 [24].
Postmultiplying (6) by $\mathbf{u}(t)=\left[u^{1}(t), \ldots, u^{M}(t)\right]$ derives

$$
\mathbf{R}_{N}=\mathbf{R}_{u}(0)-\sum_{k=1}^{p} \mathbf{R}_{u}(k \Delta t) .
$$

The vector $\mathbf{N}(t)$ of random series, having $\mathbf{R}_{N}$ as their cross-correlation matrix, can be obtained by the linear combination

$$
\begin{gathered}
\mathbf{N}(t)=\mathbf{L n}(t), \\
\mathbf{n}(t)=\left[n^{1}(t), \ldots, n^{M}(t)\right]^{T},
\end{gathered}
$$

where $\mathbf{n}(t)$ is a set of $M$ independent random processes with zero mean and unit variance and $\mathrm{L}$ is a lower triangular matrix and can be calculated by a Cholesky factorization of $\mathbf{R}_{N}$ and

$$
\mathbf{R}_{N}=\mathbf{L L}^{T} \text {. }
$$

Substituting $\psi$ (obtained from (10)) and $\mathbf{N}(t)$ (obtained from (17)) into (6), $\mathbf{u}(t)$, including $M$ series of fluctuating wind speed, is obtained.

Based on the AR model, the fluctuating wind speeds at the height of $5 \mathrm{~m}, 15 \mathrm{~m}, 25 \mathrm{~m}, 35 \mathrm{~m}, 45 \mathrm{~m}, 55 \mathrm{~m}$, and $65 \mathrm{~m}$ in the wind farm are simulated. For simplicity, the wind speed histories at the height of $5 \mathrm{~m}, 35 \mathrm{~m}$, and $65 \mathrm{~m}$ are shown in Figures 4(a)-4(c), respectively. The simulation parameters are defined as follows: $p=4$, point number $=7, \Delta t=0.1 \mathrm{sec}$, and $\Delta \omega=0.01 \mathrm{~Hz}$. 
3.3. Verification of the Simulated Wind Speed. In order to verify the simulated wind speed history, the PSD of the simulated wind is compared with that of the target spectrum (see (3)) in Figure 5. It can be seen that the simulated spectrum agrees well with the target spectrum in the frequency domain, which implies that the simulated wind has a similar power distribution as the natural wind and can be used to calculate the structural typhoon-induced response.

3.4. Wind Load Calculation. The wind rotor is a complex aerodynamic system that converts wind energy into mechanical power. The blade element theory is commonly used to calculate the wind load acting on the rotating rotor. Considering that the wind turbine should be shut down before the coming typhoon, the aerodynamic force acting on the rotor can be estimated by

$$
\mathbf{F}_{R}(t)=C_{D} \rho \mathbf{u}_{T}^{2}(t) A,
$$

where $C_{D}$ is the equivalent drag efficient of the rotor and 1.1 is used here [25], $\rho$ is the air density, $\mathbf{u}_{T}(t)$ is the total wind speed at the hub height, and $A$ is the swept area.

The relationship between wind speed and wind pressure under ambient conditions is described by the Bernoulli equation:

$$
\mathbf{w}(t)=\frac{\gamma}{2 g} \mathbf{u}_{T}^{2}(t) \approx \frac{\mathbf{u}_{T}^{2}(t)}{1630},
$$

where $\mathbf{w}(t)$ is the wind pressure, $\gamma$ is the unit weight of air, and $g$ is the gravitational acceleration.

Assuming that the wind speed is parallel to the normal direction of the rotor, which is the most unfavorable condition for the support structure, the wind load acting on each element of tower can be calculated by the following expression:

$$
\mathbf{F}_{e}(t)=\mu_{s e} A_{e} \mathbf{w}(t),
$$

where $A_{e}$ is the element area and $\mu_{s e}$ is the shape coefficient of the element.

\section{FE Analysis}

4.1. Differential Equation of Motion. In order to study the dynamic responses of the wind power structure subjected to typhoon load varying in time, a transient dynamic analysis should be conducted. Based on the D'Alemberts principle and due to the discretization process of a continuous structure with FEs, the following equation of motion can be derived:

$$
\mathbf{M} \ddot{\mathbf{u}}_{N}(t)+\mathbf{C} \dot{\mathbf{u}}_{N}(t)+\mathbf{K} \mathbf{u}_{N}(t)=\mathbf{f}(t),
$$

where $\mathbf{M}, \mathbf{C}$, and $\mathbf{K}$ denote the structural mass, damping, and stiffness matrices, respectively, $\ddot{\mathbf{u}}_{N}(t), \dot{\mathbf{u}}_{N}(t)$, and $\mathbf{u}_{N}(t)$ are the vectors of nodal accelerations, velocities, and displacements, respectively, and $\mathbf{f}(t)$ is the vector of applied forces.

The Newmark integration method, which is an implicit time integration algorithm, is employed to solve (23).

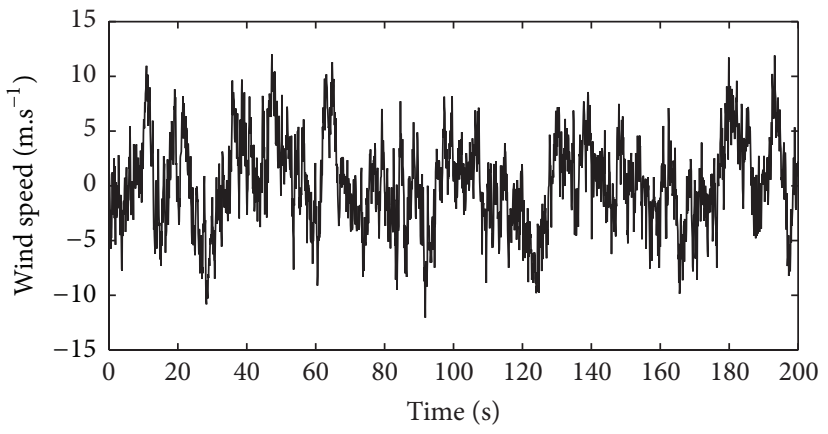

(a) At the height of $5 \mathrm{~m}$

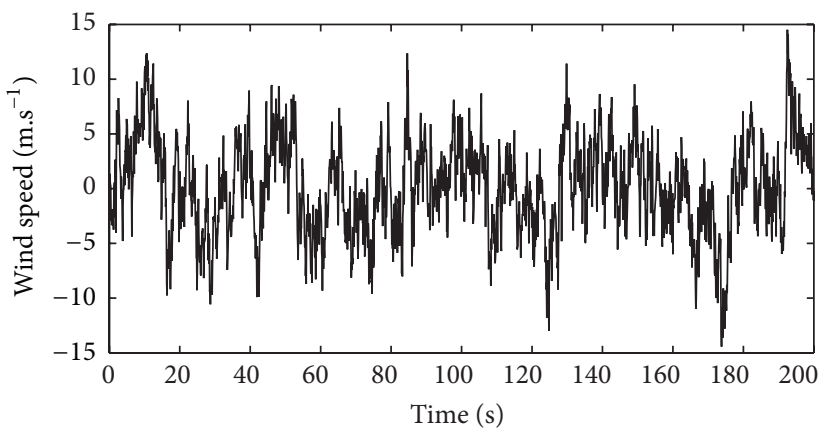

(b) At the height of $35 \mathrm{~m}$

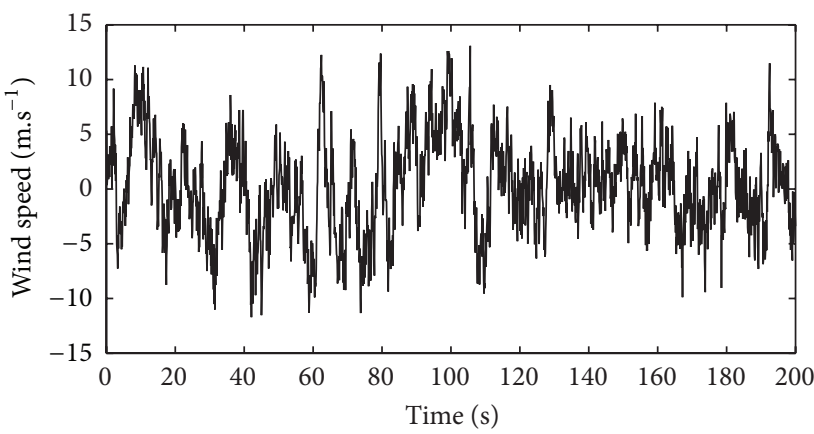

(c) At the height of $65 \mathrm{~m}$

FIGURE 4: Fluctuating wind speed histories at different heights.

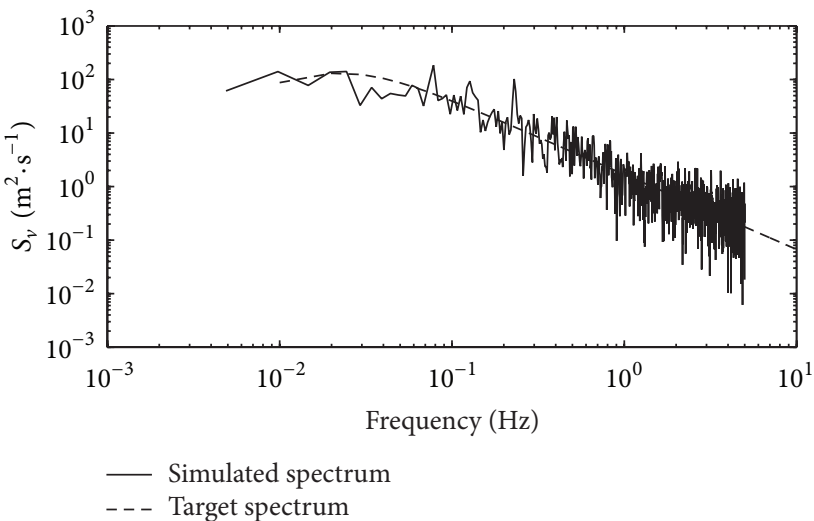

FIGURE 5: Comparison between the target spectrum and the simulated spectrum. 
TABLE 2: Dimensions of the tower.

\begin{tabular}{lcccr}
\hline \multirow{2}{*}{ Segment } & Lower diameter $(\mathrm{m})$ & Upper diameter $(\mathrm{m})$ & Height $(\mathrm{m})$ & \multicolumn{2}{c}{ Shell thickness $(\mathrm{m})$} & Lower & Upper \\
\hline Lower & 4.0 & 3.6 & 17.6 & 0.022 \\
Middle & 3.6 & 3.0 & 22.4 & 0.022 \\
Upper & 3.2 & 3.0 & 22.4 & 0.016 \\
Anchor ring & 4.0 & 4.0 & 0.6 & 0.016 \\
\hline
\end{tabular}

TABLE 3: Material parameters.

\begin{tabular}{lcccc}
\hline Part & Elastic modulus $\left(\mathrm{N} \cdot \mathrm{m}^{-2}\right)$ & Density $\left(\mathrm{kg} \cdot \mathrm{m}^{-3}\right)$ & Poison's ration & Yield strength $(\mathrm{MPa})$ \\
\hline Nacelle & $2.1 \times 10^{11}$ & 563 & 0.3 & $/$ \\
Rotor & $2.1 \times 10^{11}$ & 44.8 & 0.3 & $/$ \\
Tower & $2.1 \times 10^{11}$ & 7850 & 0.3 & 345 \\
Pile cap & $3.25 \times 10^{10}$ & 2500 & 0.167 & $/$ \\
\hline
\end{tabular}

It should be pointed out that damping plays an important role in the dynamic response of the wind power structure. Ambient vibration tests are always employed to estimate the damping ratio because of its strong advantage of being practical and economical, using the freely available ambient wind wave excitation. Shirzadeh et al. [26] measured the damping ratio of a $3 \mathrm{MW}$ offshore wind turbine under ambient vibration, and the measured values are $1.05 \%$ and $1.27 \%$ for, respectively, the first FA mode and the first SS mode. Similarly, Ma et al. [27] obtained the damping ratio of a 1.5 MW land-based wind turbine tower. Considering that the wind turbine and support structure of the latter case is the same as this study, the measured damping ratio $1.75 \%$ is used here.

4.2. Modal Analysis Algorithm. A modal analysis is performed to calculate the natural frequencies of the wind power structure. Omitting the damping matrix and force vector in (23), the free vibration equation of the wind power structure for eigenvalue analysis is obtained

$$
\mathbf{M} \ddot{\mathbf{u}}_{N}(t)+\mathbf{K} \mathbf{u}_{N}(t)=\mathbf{0} .
$$

Assume the general form of the solution is

$$
\mathbf{u}_{N}(t)=\varphi \sin (\omega t+\phi) .
$$

Equation (24) becomes

$$
\left|\mathbf{K}-\omega^{2} \mathbf{M}\right|=\mathbf{0} .
$$

The block Lanczos method is a very efficient and robust algorithm to perform a modal analysis for large models; thus it is employed on the platform of ANSYS [28].

4.3. FE Model. As mentioned before, $1.5 \mathrm{MW}$ wind turbines are installed in Dongtai wind farm. The tower is $62.75 \mathrm{~m}$ in height (the hub height is $65 \mathrm{~m}$ ) and is fixed on the pile cap by an anchor ring. The tower consists of 3 segments of cylinder with dimensions shown in Table 2. The material parameters of the nacelle, rotor, tower, and pile cap are listed in Table 3.
There are thirty PHC piles arranged under the pile cap. Six of them are along the inner circle with a diameter of $4.1 \mathrm{~m}$, and the others are along the outer circle with a diameter of $16.8 \mathrm{~m}$, as shown in Figure 6 . Based on pile tests, the horizontal stiffness and vertical stiffness of the pile are $E_{h}=1.8 \times 10^{7} \mathrm{~N} \cdot \mathrm{m}^{-2}$ and $E_{v}=1.9 \times 10^{8} \mathrm{~N} \cdot \mathrm{m}^{-2}$, respectively.

The FE model of the wind power structure is shown in Figure 7. Totally, 14898 elements are used with the types listed in Table 4. Considering that the failure mechanism of blade is beyond the scope of this study, solid element is employed to simulate the rotor with an equivalent mass.

Table 5 compares the natural frequencies of the structure with piles (case 1) and the structure fixed on a rigid foundation (case 2). It can be seen that the primary and secondary frequencies are around $0.41 \mathrm{~Hz}$ in both cases, which is close to the predominant frequency of typhoon. Consequently, a resonance is easy to happen. Furthermore, the natural frequencies of wind power structure in case 2 are higher than that in case 1, especially for 6th to 10th orders frequency. It reveals that piles decrease the structural stiffness and should be taken into account in the structural dynamic analysis.

\section{Failure Mode Analysis}

5.1. Horizontal Displacement of the Hub. As a typical slender structure, wind power structure is sensitive to horizontal displacement. Consequently, the horizontal displacement of the hub $\left(U_{h}\right)$ is usually regarded as a safety control index of the wind power structure. In Figure 8 , it can be seen that the hub moves from $-0.160 \mathrm{~m}$ to $1.125 \mathrm{~m}$, and the maximum displacement is under the limit value of $1.3 \mathrm{~m}$, which is $1 / 50$ of the hub height [29].

5.2. Stress of the Tower. Under the wind load, the vertical stress of the tower, which is predominant, is small at the top and large at the bottom. Accordingly, the shell thickness of the tower gradually increases from the top to the bottom. However, the tower bottom is still prone to buckling. Figures 9(a) and 9(b) show the Von-Mises equivalent stress histories of the lowest element in the windward side and the leeward side of 
TABLE 4: Element types of structural components.

\begin{tabular}{llcccc}
\hline Part & Nacelle & Rotor & Tower & Pile cap & PHC piles \\
\hline Element type & Solid 45 & Solid 45 & Shell 63 & Solid 45 & Combine 14 \\
\hline
\end{tabular}

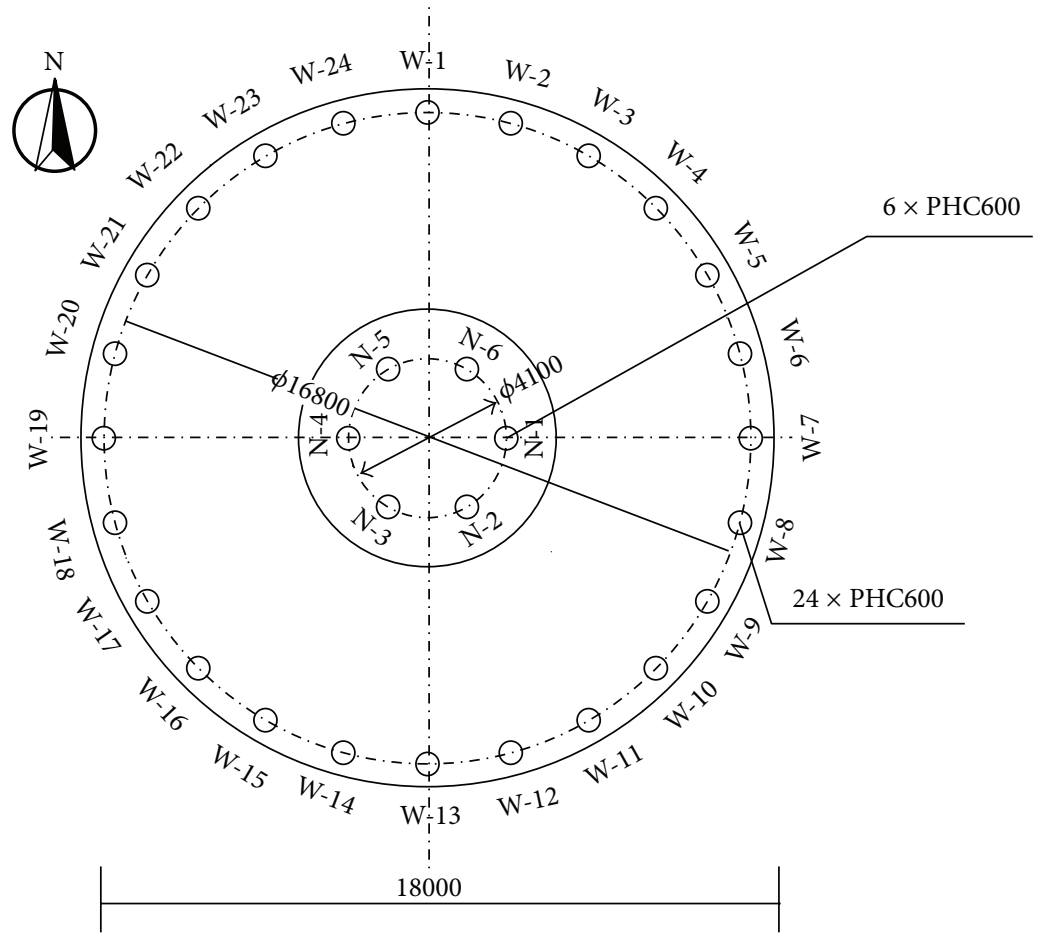

Figure 6: Arrangement of piles.

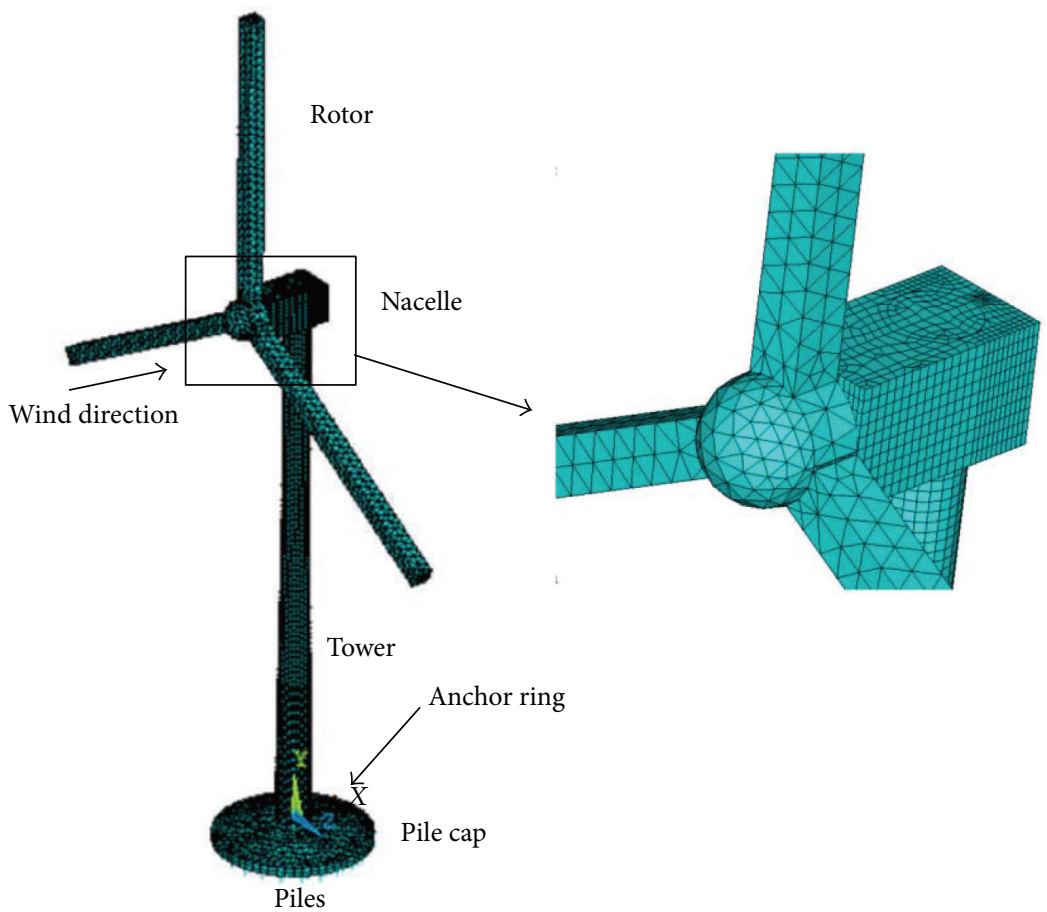

FIGURE 7: FE model of the wind power structure with piles. 
TABLE 5: Natural frequencies of wind power structures.

\begin{tabular}{lccc}
\hline $\begin{array}{l}\text { Frequency } \\
\text { order }\end{array}$ & Case 1: $f_{1}(\mathrm{~Hz})$ & Case 2: $f_{2}(\mathrm{~Hz})$ & $\left(f_{2}-f_{1}\right) / f_{1}$ \\
\hline 1 & 0.4093 & 0.4139 & $1.12 \%$ \\
2 & 0.4150 & 0.4198 & $1.16 \%$ \\
3 & 1.6073 & 1.6251 & $1.11 \%$ \\
4 & 2.1899 & 2.2304 & $1.85 \%$ \\
5 & 2.4607 & 2.5216 & $2.47 \%$ \\
6 & 3.4773 & 4.7378 & $36.25 \%$ \\
7 & 3.5011 & 4.9219 & $40.58 \%$ \\
8 & 4.6193 & 5.8408 & $26.44 \%$ \\
9 & 4.7378 & 5.8443 & $23.35 \%$ \\
10 & 4.9218 & 6.1542 & $25.04 \%$ \\
\hline
\end{tabular}

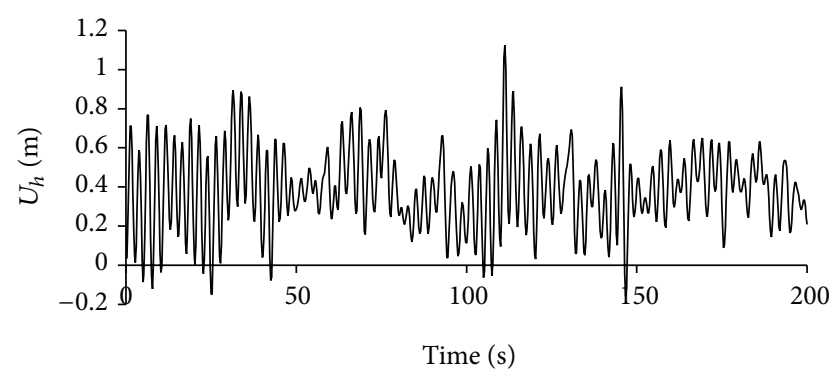

FIGURE 8: The horizontal displacement history of the hub.

the tower, respectively. Obviously, at quite a lot of time steps, the stress of the lowest elements, not only at the windward side but also at the leeward side, is over the steel's yield strength. As a result, buckling originates from the tower bottom. Considering that the maximum stress appears at time $=$ $111.25 \mathrm{sec}$, the corresponding equivalent stress distributions are described in Figure 10. Due to the bending stress and the stress concentration, the stress reaches the maximum at the junction of the lower segment and the anchor ring. The yield range looks spindle-like with the height of $0.5 \mathrm{~m}$ approximately.

5.3. Stress of the Anchor Ring. Owing to the large thickness of the anchor ring, the equivalent stress decreases rapidly and is under the steel's yield strength at most time steps. Assuming the stress concentration is eliminated by engineering means, the yield possibility of the anchor ring can be reduced effectively (Figure 11).

The maximum equivalent stress of the anchor ring also appears at time $=111.25 \mathrm{sec}$ and the stress distribution is described in Figure 12. It is shown that the ring protrudes at the windward side and indents at the leeward side, and it can be regarded as a typical buckling mode of the tower [2].

5.4. Axial Force of the Unfavorable Piles. Each foundation pile bears different bending moment based on moment distribution method. Consequently, the piles at the windward side and the leeward side on the outer circle are the most unfavorable, and their axial force histories are shown in Figure 13.

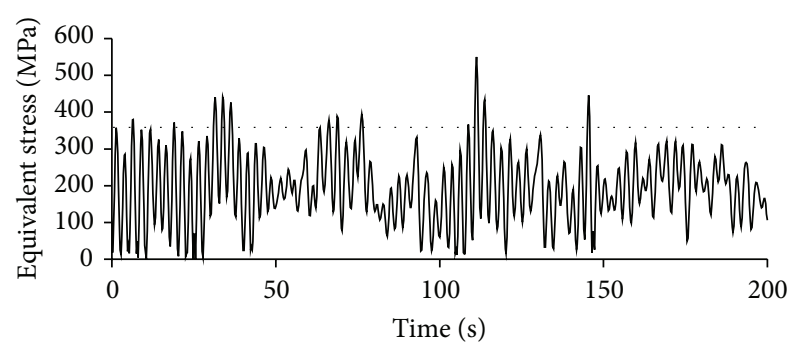

(a) The element at the windward side

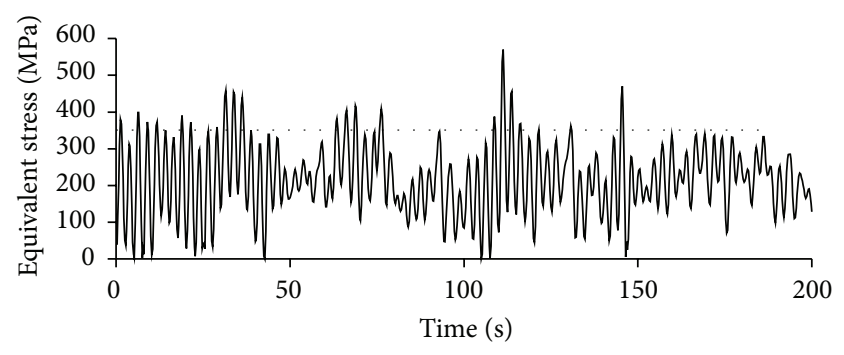

(b) The element at the leeward

FIGURE 9: Von-Mises equivalent stress history at the bottom of tower.

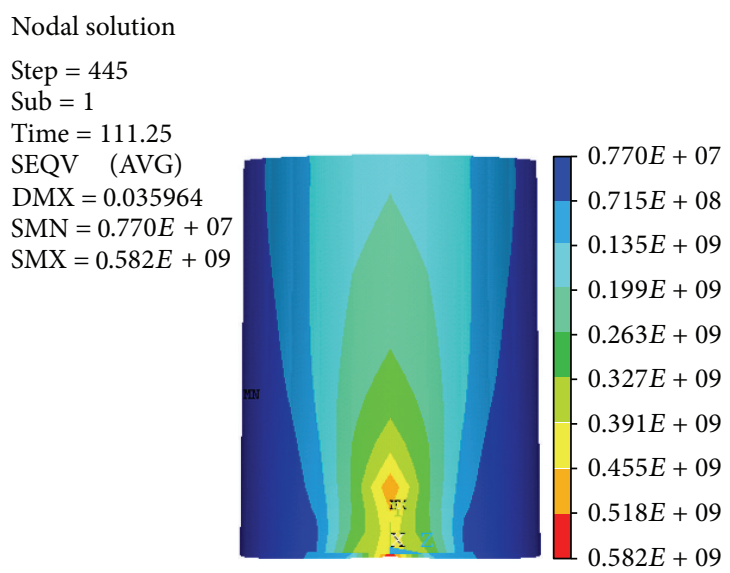

(a) At the windward side

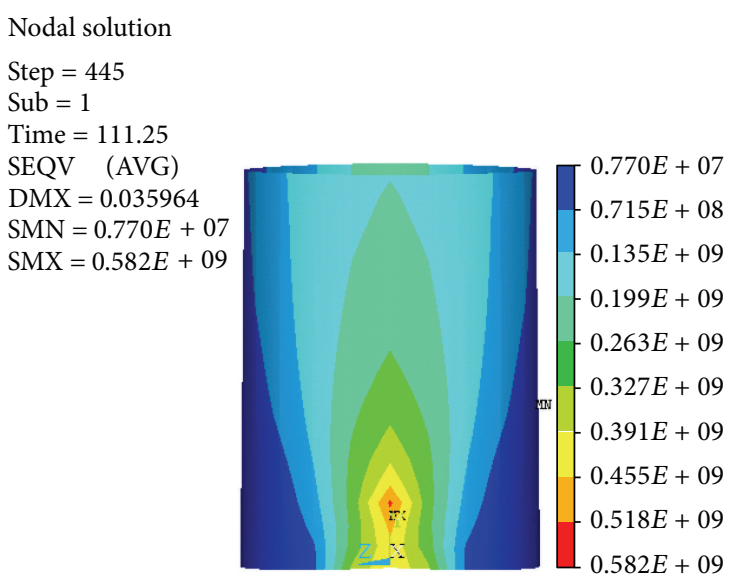

(b) At the leeward side

FIGURE 10: Von-Mises equivalent stress at the bottom of tower while time $=111.25 \mathrm{sec}$. 


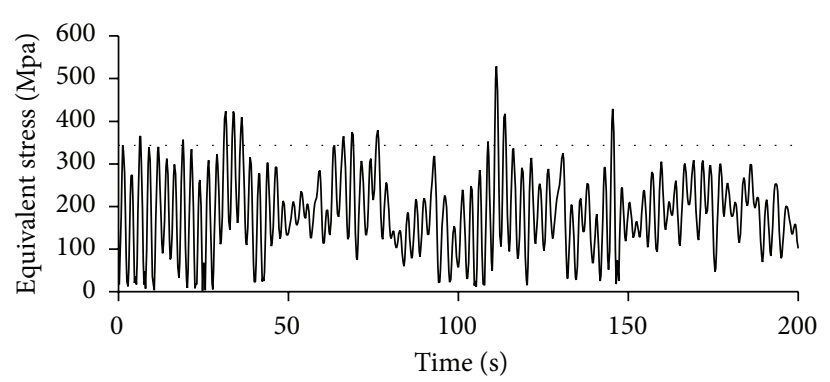

(a) The element at the windward

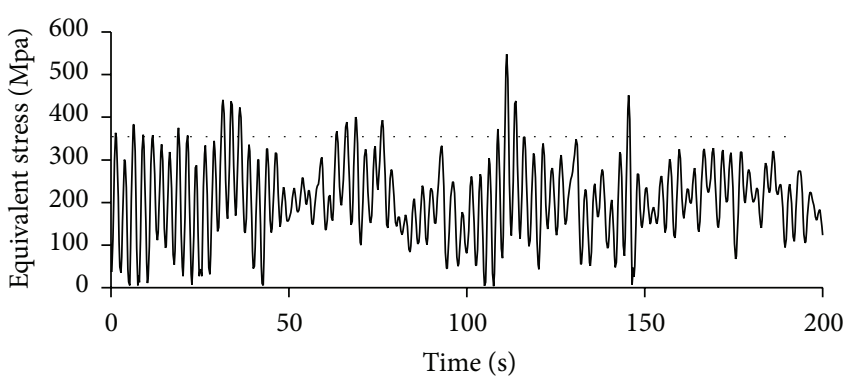

(b) The element at the leeward

FIGURE 11: Von-Mises equivalent stress histories at the bottom of anchor ring.

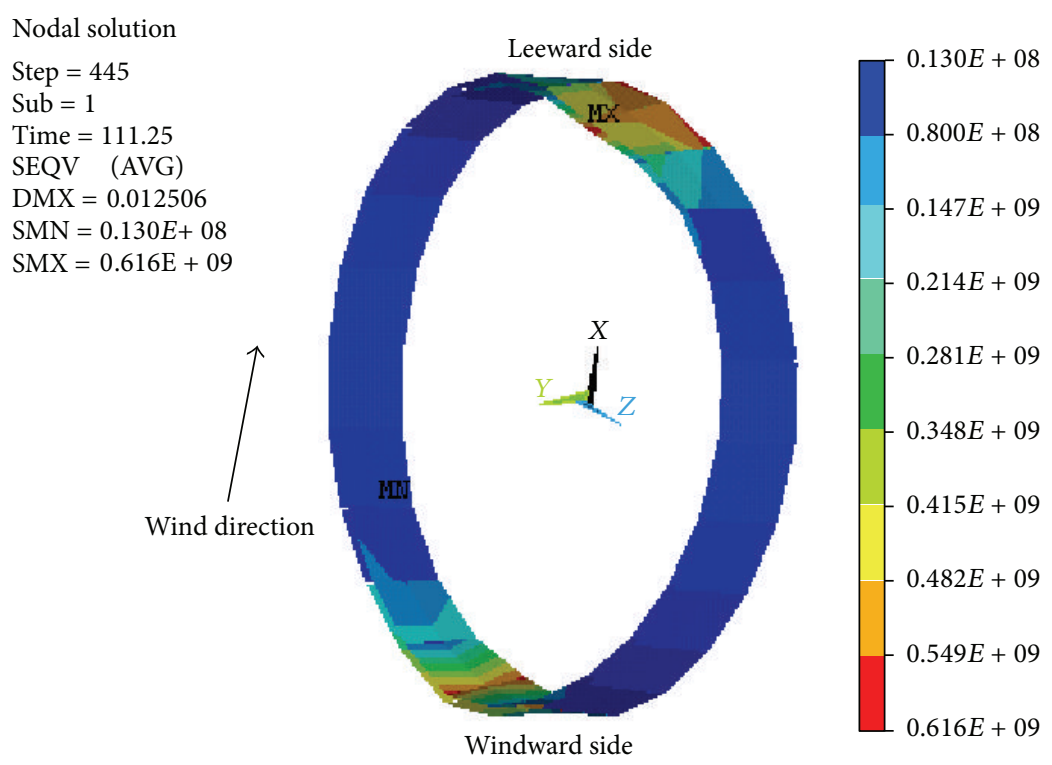

FIGURE 12: Von-Mises equivalent stress distribution of the anchor ring.

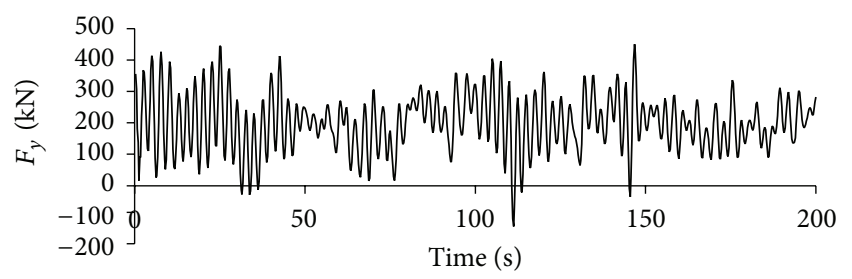

(a) Pile at the windward side

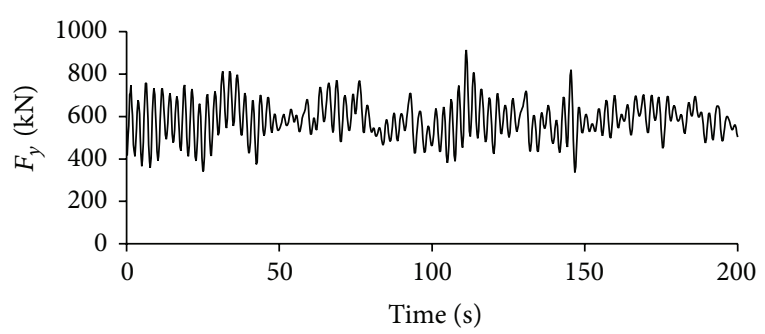

(b) Pile at the leeward side

FIGURE 13: Axial force of the most unfavorable piles.
Pile tests that provided the ultimate compress and tensile bearing capacity of single pile are $1250 \mathrm{kN}$ and $470 \mathrm{kN}$, respectively, and the ultimate tensile bearing capacity of the pile body is $2500 \mathrm{kN}$. Thus, the pile foundation has enough deign safety margin in this case.

\section{Conclusion}

Based on the classical AR model and a regional PSD model, the wind field of typhoon in a coastal wind farm is simulated and verified. A FE model of the wind power structure, including nacelle, rotor, tower, pile cap, and PHC piles, is established. Modal analysis shows that the natural frequencies of the wind power structure fixed on rigid foundation are higher than that of the structure with piles, which implies that piles decrease the structural stiffness and should be taken into account in the structural dynamic analysis. The primary and secondary frequencies of the structure are close to the predominant frequency of typhoon, leading to a resonance between the structure and the wind. Dynamic analysis reveals 
that tower buckling is the most prone failure mode of the wind power structure subjected to typhoon. The stress concentration at the junction of tower and anchor ring should be eliminated by welding seam with gradient thickness or bolts with enough strength. Although all piles are verified to be safe in this case, they still have to be checked, especially the unfavorable piles, under the conditions of typhoon.

\section{Conflict of Interests}

The authors declare no possible conflict of interests.

\section{Acknowledgments}

The supports of National Natural Science Foundation of China (Grant no. 51308307), Zhejiang Provincial Natural Science Foundation of China (Grant no. LQ13E080008), Ningbo Natural Science Foundation (Grant no. 2014A610169), and Zhejiang Provincial Research Project of Technology Application for Public Welfare (Grant no. 2014C33009) are highly appreciated.

\section{References}

[1] GWEC, "Global wind report-annual market update 2012," http://www.gwec.net/wp-content/uploads/2012/06/Annual_ report_2012_LowRes.pdf.

[2] T. Ishihara, A. Yamaguchi, K. Takahara, T. Mekaru, and S. Matsuura, "An analysis of damaged wind turbines by Typhoon Maemi in 2003," in Proceedings of the 6th Asia-Pacific Conference on Wind Engineering, pp. 1413-1428, Seoul, Republic of Korea, 2005.

[3] Z. Q. Li, S. J. Chen, H. Ma, and T. Feng, "Design defect of wind turbine operating in typhoon activity zone," Engineering Failure Analysis, vol. 27, pp. 165-172, 2012.

[4] IEC 61400-1 Ed.3, "International electro-technical commission," Wind turbines-Part 1: Design requirements, 2005.

[5] N. E. Clausen, S. Ott, N. J. Tarp-Johansen et al., "Design of wind turbines in an area with tropical cyclones," in Proceedings of the European Wind Energy Conference, 2006.

[6] J. S. Chou, C. K. Chiu, I. K. Huang, and K. N. Chi, "Failure analysis of wind turbine blade under critical wind loads," Engineering Failure Analysis, vol. 27, pp. 99-118, 2013.

[7] M. Karimirad and T. Moan, "Wave and wind induced dynamic response of a spar-type offshore wind turbine," Journal of Waterway, Port, Coastal, and Ocean Engineering, vol. 138, no. 1, pp. 9-20, 2011.

[8] H. Zhang, H. Sun, L. Liu, and M. Dong, "Resonance mechanism of wind-induced isolated aqueductwater coupling system," Engineering Structures, vol. 57, pp. 73-86, 2013.

[9] M. Karimirad and T. Moan, "Stochastic dynamic response analysis of a tension leg spar-type offshore wind turbine," Wind Energy, vol. 16, no. 6, pp. 953-973, 2013.

[10] GB/T 19201-2006, "Grade of Tropical Cyclones," (Chinese).

[11] H. Tennekes, "The logarithmic wind profile," Journal of Atmospheric Sciences, vol. 30, pp. 234-238, 1973.

[12] J. B. Roberts and P. D. Spanos, Random Vibration and Statistical Linearization, John Wiley \& Sons, Chichester, UK, 1990.
[13] T. von Karman, "Progress in the statistical theory of turbulence," Proceedings of the National Academy of Sciences of the United States of America, vol. 34, no. 11, pp. 530-539, 1948.

[14] A. G. Davenport, "The spectrum of horizontal gustiness near the ground in high winds," Quarterly Journal of the Royal Meteorological Society, vol. 87, no. 372, pp. 194-211, 1961.

[15] E. Simiu, "Wind spectra and dynamic alongwind response," Journal of the Structural Division, vol. 100, no. 9, pp. 1897-1910, 1974.

[16] Y. Shi, W. Lu, and Y. Zhong, "The study of typhoon characteristics in the Shanghai region," in Proceedings of the 2nd National Conference on Wind Effect, 1988, (Chinese).

[17] P. Ailliot, V. Monbet, and M. Prevosto, "An autoregressive model with time-varying coefficients for wind fields," Environmetrics, vol. 17, no. 2, pp. 107-117, 2006.

[18] L. V. Hansen and T. L. Thorarinsdottir, "A note on moving average models for Gaussian random fields," Statistics Probability Letters, vol. 83, no. 3, pp. 850-855, 2013.

[19] H. Zhang, L. Liu, M. Dong, and H. Sun, "Analysis of windinduced vibration of fluidstructure interaction system for isolated aqueduct bridge," Engineering Structures, vol. 46, pp. 2837, 2013.

[20] R. G. Kavasseri and K. Seetharaman, "Day-ahead wind speed forecasting using f-ARIMA models," Renewable Energy, vol. 34, no. 5, pp. 1388-1393, 2009.

[21] A. Iannuzzi and P. Spinelli, "Artificial wind generation and structural response," Journal of Structural Engineering, vol. 113, no. 12, pp. 2382-2398, 1987.

[22] Y. Q. Li and S. L. Dong, "Random wind load simulation and computer program for large-span spatial structures," Spatial Structures, vol. 7, pp. 3-12, 2001 (Chinese).

[23] M. Shiotani and H. Avai, "Lateral structures of gusts in high winds," in Proceedings of the International Conference on Wind Effects on Buildings and Structures, 1967.

[24] X. T. Zhang, "The spatial correlations and conversion factor of wind -excited random vibration for towers and tall buildings," Journal of Tongji University, vol. 2, 1982, (Chinese).

[25] Q. Y. Li, Design of Small Wind Turbine, Machinery Industry Press, Beijing, China, 1986, (Chinese).

[26] R. Shirzadeh, C. Devriendt, M. A. Bidakhvidi, and P. Guillaume, "Experimental and computational damping estimation of an offshore wind turbine on a monopole foundation," Journal of Wind Engineering and Industrial Aerodynamics, vol. 120, pp. 96106, 2013.

[27] R. L. Ma, Y. Q. Ma, H. Q. Liu, and J. L. Chen, "Ambient vibration test and numerical simulation for modes of wind turbine towers," Journal of Vibration and Shock, vol. 30, no. 5, pp. 152-155, 2011 (Chinese).

[28] ANSYS, User's Manual: Structural Analysis Guide, ANSYS Inc., 1998.

[29] GB50135-2006, "Code for design of high-rising structures," (Chinese). 


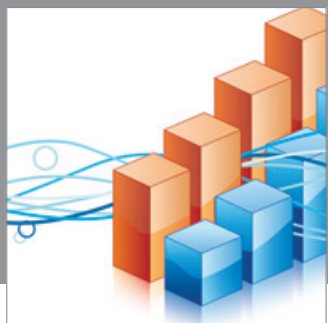

Advances in

Operations Research

mansans

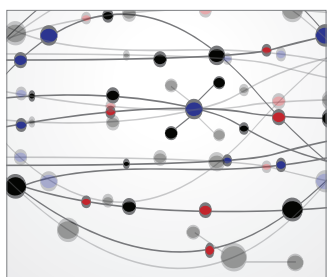

The Scientific World Journal
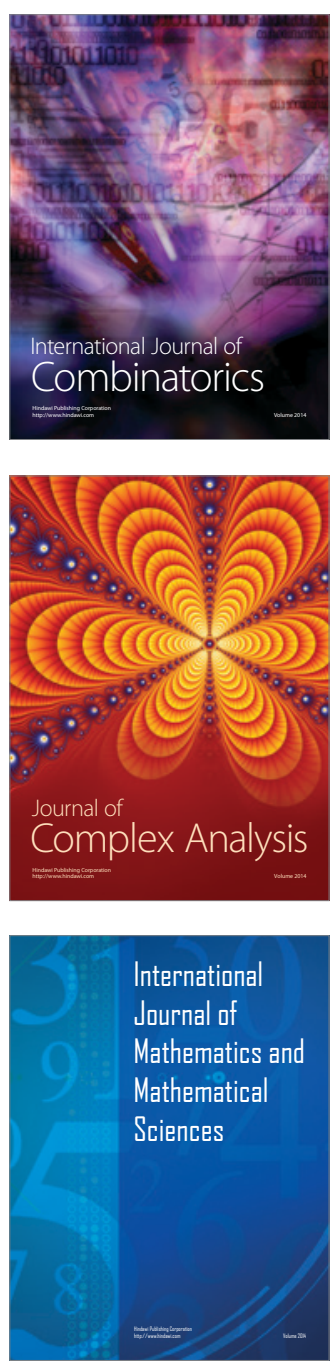
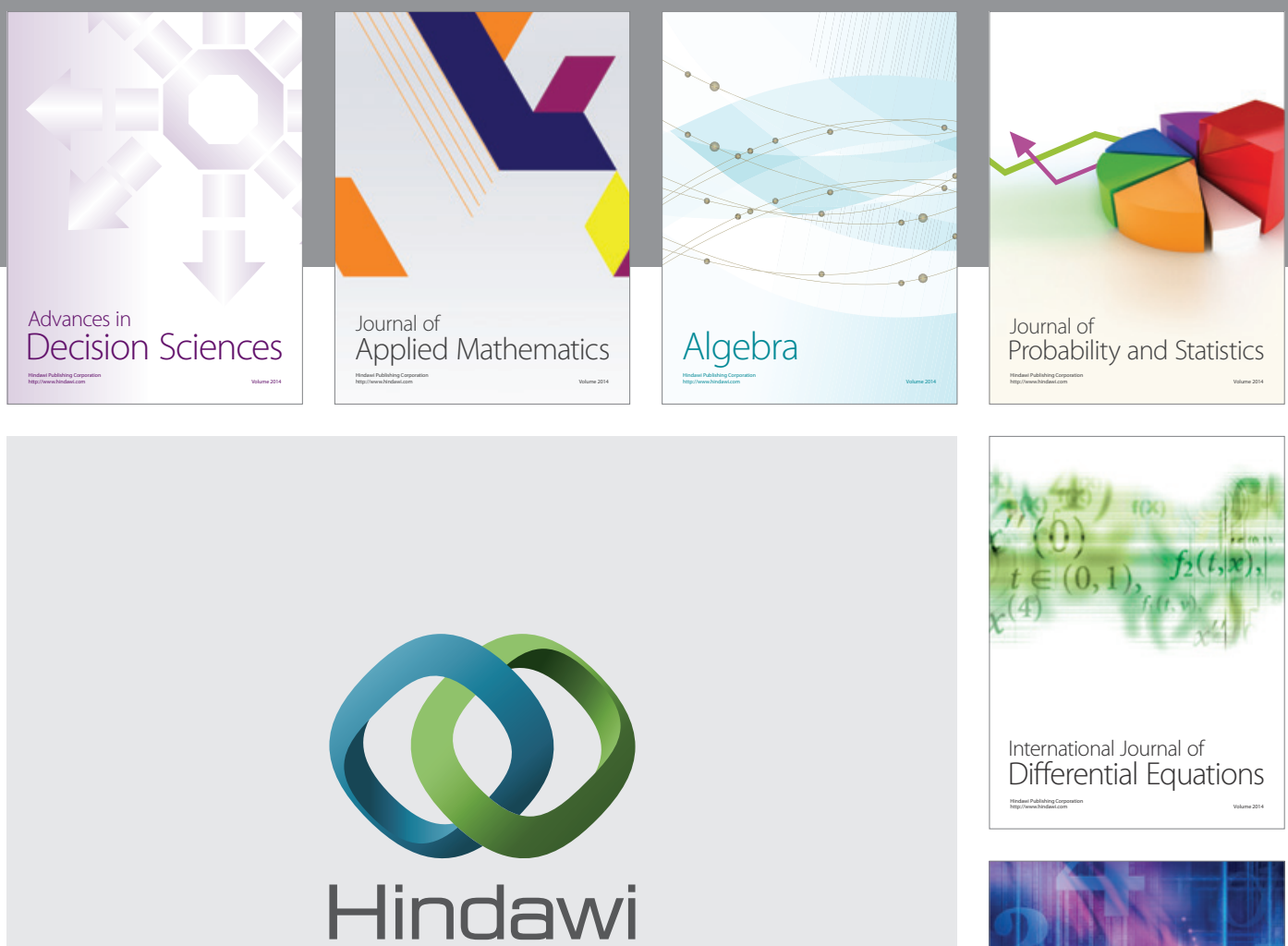

Submit your manuscripts at http://www.hindawi.com
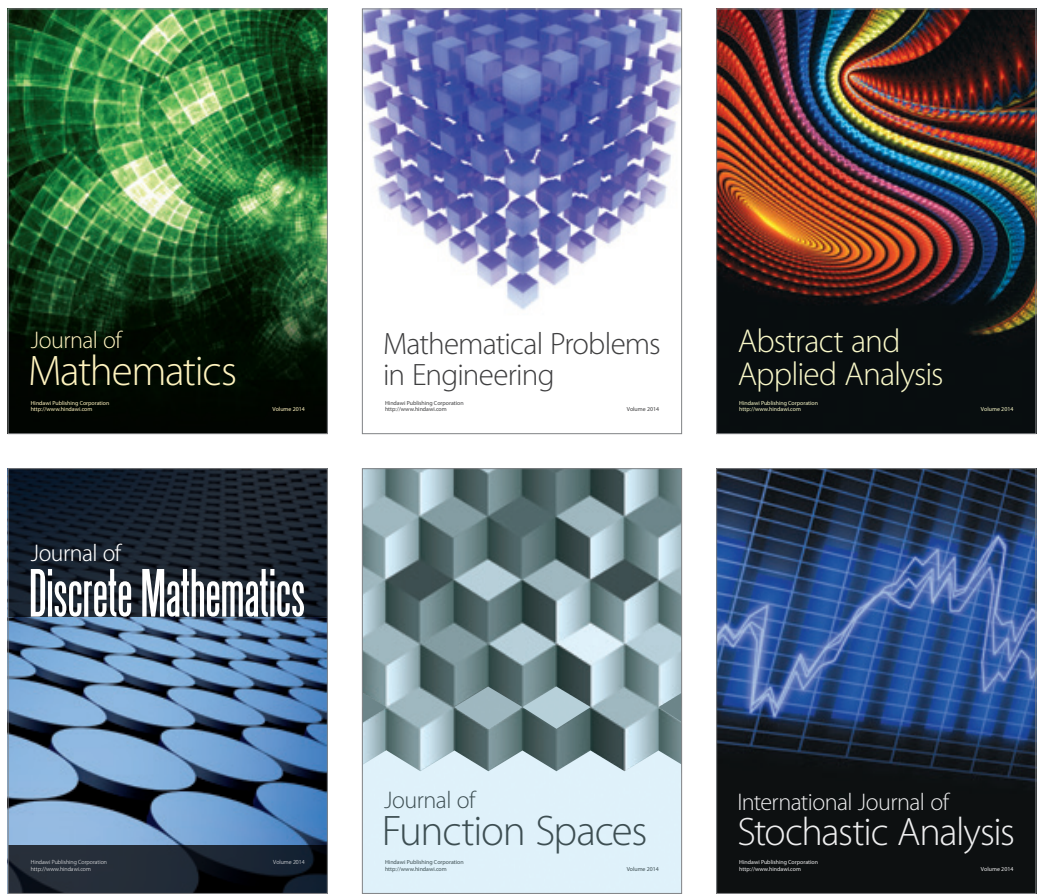

Journal of

Function Spaces

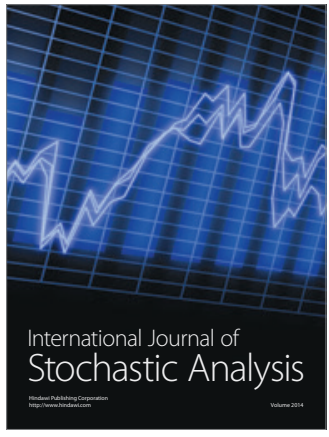

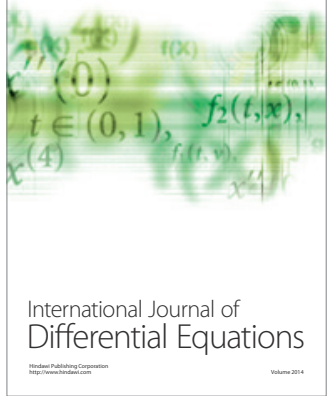
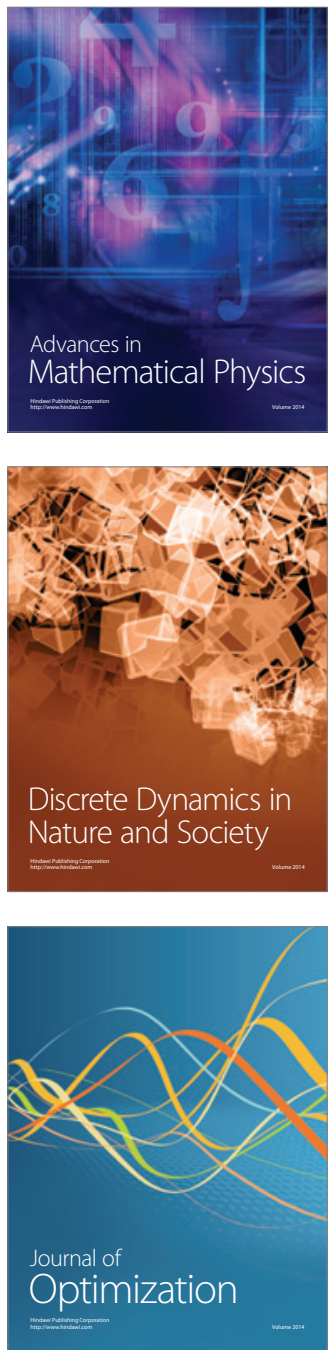